\title{
KEWENANGAN PELAKSANA TUGAS MENTERI DALAM MENGAMBIL KEPUTUSAN DAN TINDAKAN YANG BERSIFAT STRATEGIS BERDASARKAN UNDANG - UNDANG NOMOR 30 TAHUN 2014 TENTANG ADMINISTRASI PEMERINTAHAN
}

\author{
Sigit Egi Dwitama \\ Masena Benhard Advocates Lawfirm and Partners, Jakarta \\ Email : sigitegidwitama94@yahoo.com
}

\begin{abstract}
One form of decree that is included in the scope of state administration is a Ministerial Decree, which is a decision determined and issued by a minister who is always concreteindividual in the form of administrative stipulations (beschikking). However, not all departments and/or government officials such as the Minister have the authority to form these decisions, because in forming decisions can be seen from the status of government officials as an example of the Ad Interim Minister who does not have the authority to issue strategic decisions. But different problems arise when there is Ad Interim of Energy and Mineral Resources Minister Luhut Binsar Pandjaitan issued Decree Number 6752 K / 70 / MEM / 2016 concerning Dissolution of Ad Hoc Organizational Units in the Ministry of Energy and Mineral Resources, which basically was a strategic decision.

This study is a legal research using a normative juridical approach and descriptive analytical research specifications. The data used in this study are secondary data consisting of primary, secondary and tertiary legal materials. Data obtained through library studies and field research in the form of legislation, books, journals, and electronic media.

The results of this study consist of 2 (two) analyzes, namely First, the position of the Acting Decree of the Minister of ESDM does not have legal validity because there is a disability when viewed from the aspect of authority, formation process, and the purpose of its establishment with legislation and AUPB and Second, towards legal validity which is not possessed by the Minister's decree executor, the decree becomes invalid and a mechanism is needed to cancel the decree.
\end{abstract}

Keywords: Authority of the Minister, Ad Interim Minister, Decree.

\section{PENDAHULUAN}

Menteri memiliki kedudukan sebagai pejabat administrasi negara yang bergerak dibidangnya masing-masing, selain itu Menteri juga memiliki kedudukan sebagai pemimpin tertinggi yang mengepalai suatu kementerian. Keberadaan jabatan-jabatan Menteri dalam lingkup eksekutif merupakan selaku pelaksana teknis pemerintahan sebagaimana yang diatur dalam Pasal 17 ayat (1), (2), (3), dan (4) Undang-Undang Dasar Negara Kesatuan Republik Indonesia Tahun 1945. Dalam sistem ketatanegaraan Indonesia, jabatan Menteri merupakan jabatan yang bersifat politis. Dengan kata lain, Menteri diangkat dan diberhentikan oleh Presiden sesuai dengan kebijakan politik 
Presiden. Sebagai bagian dari kekuasaan eksekutif, menteri memiliki kewenangan untuk membentuk peraturan perundang-undangan maupun peraturan kebijakan, termasuk juga untuk mengeluarkan surat keputusan tata usaha negara (KTUN).

Surat keputusan KTUN tersendiri sangatlah beragam bentuknya. Selain dalam bentuk surat keputusan (SK), terapat pula keputusan dalam bentuk lain, seperti Izin Usaha Industri, Surat Keterangan Kelakuan Baik, Akte Kelahiran, Sertifikat Hak atas Tanah, Surat Izin Mengemudi, dan lain sebagainya.

Salah satu bentuk surat keputusan yang termasuk kedalam ruang lingkup tata usaha negara adalah Surat Keputusan Menteri. Surat Keputusan Menteri pada dasarnya adalah keputusan yang ditetapkan dan diterbitkan oleh menteri yang selalu bersifat konkretindividual berupa penetapan administratif (beschikking). Adapula yang bersifat mengatur (regeling) abstrak-umum.

Surat keputusan yang dikeluarkan oleh badan dan/atau pejabat pemerintahan juga mempunyai landasan yang jelas ataupun kewenangan yang sah dalam setiap pembentukan keputusan, akan tetapi tidak semua badan dan/atau pejabat pemerintahan mempunyai kewenangan untuk membentuk keputusan. Kewenangan pejabat pemerintahan dalam membentuk keputusan dapat dilihat dari status pejabat pemerintahan tersebut, karena terdapat pengecualian apabila pejabat pemerintahan tersebut merupakan pejabat pemerintahan non definitif (pelaksana tugas rutin). Pasal 14 ayat (2) Undang-Undang Nomor 30 Tahun 2014 tentang Administrasi Pemerintahan berbunyi :

“2) Pejabat yang melaksanakan tugas rutin sebagaimana dimaksud pada ayat (1) huruf $\mathrm{b}$ terdiri atas :

a. Pelaksana harian yang melaksanakan tugas rutin dari pejabat definitif yang berhalangan sementara; dan

b. Pelaksana tugas yang melaksanakan tugas rutin dari pejabat definitif yang berhalangan tetap."

Sejalan dengan penjelasan tersebut, terdapat suatu permasalahan terhadap pengambilan keputusan menteri yang dilakukan oleh Pelaksana Tugas Menteri ESDM Luhut Binsar Pandjaitan yang ditunjuk oleh Presiden menggantikan Menteri ESDM yang sebelumnya, yaitu dimana semasa menjabat Luhut Pandjaitan telah mengeluarkan Surat Keputusan Nomor 6752 K/70/MEM/2016 Tentang Pembubaran Unit Organisasi Ad Hoc di Lingkungan Kementerian Energi dan Sumber Daya Mineral. Adapaun unit-unit ad hoc yang dibubarkann Nasional (UP3KN), Komite Eksplorasi Nasional dan Tim Percepatan Pengembangan Energi Baru Terbarukan (P2EBT), dan lainnya. 
Pada dasarnya PLT Menteri ESDM menurut Undang-Undang Nomor 30 Tahun 2014 tentang Administrasi Pemerintahan haruslah dinilai sebagai pejabat pemerintahan non definitif (pelaksana tugas harian) yang melakukan tugas rutin karena pejabat definitif Menteri ESDM berhalangan tetap. Pejabat non definitif (pelaksana tugas rutin) tidak berwenang mengambil keputusan dan/atau tindakan yang bersifat strategis yang berdampak pada perubahan status hukum pada aspek organisasi, kepegawaian, dan alokasi anggaran.

Dalam kasus ini sebenarnya pembatasan wewenang yang dimiliki seorang PLT jelas diatur dalam Undang-Undang Nomor 30 Tahun 2014 tentang Administrasi Pemerintahan yang tidak dapat disimpangi atau ditafsirkan lain dengan peraturan perundang-undangan di bawah Undang-Undang. Adanya perbedaan antara ketentuan dan kenyataan yang terjadi dalam pelaksanaan kewenangan pelaksana tugas menteri dalam mengambil keputusan dan tindakan yang bersifat strategis, dalam hal ini penulis bermaksud untuk menganalisis kembali permasalahan mengenai kewenangan pelaksana tugas Menteri Energi dan Sumber Daya Mineral yang mengambil keputusan dan tindakan yang bersifat strategis ini.

Dari berbagai pemasalahan tersebut dapatlah diidetifikasi persoalan-persoalan sebagai berikut :

1. Bagaimana kedudukan Surat Keputusan Nomor 6752 K/70/MEM/2016 yang dikeluarkan oleh Pelaksana Tugas Menteri ESDM dihubungkan dengan UndangUndang Nomor 30 Tahun 2014 tentang Administrasi Pemerintahan?

2. Bagaimana akibat hukum terhadap Surat Keputusan Nomor 6752 K/70/MEM/2016 yang dikeluarkan oleh Pelaksana Tugas Menteri ESDM dihubungkan dengan Undang-Undang Nomor 30 Tahun 2014 tentang Administrasi Pemerintahan ?

\section{METODE}

Spesifikasi penelitian ini adalah deskriptif analitis, dengan pendekatan Yuridis Normatif, yaitu penelitian yang bertujuan menggambarkan mengenai fakta-fakta disertai analisis yang akurat mengenai peraturan perundang-undangan yang bersumberdayi bahanbahan hukum, baik bahan hukum primer, bahan hukum sekunder maupun tersier. 
Teknik pengumpulan data dilakukan melalui Penelitian kepustakaan yakni untuk memperoleh bahan-bahan hukum baik primer, sekunder, maupun tersier. ${ }^{3}$ Bahan hukum primer adalah bahan-bahan yang berasal dari peraturan perundang-undangan, antara lain UUD 1945, Undang-Undang Nomor 30 Tahun 2014 tentang Administrasi Pemerintahan. Bahan-bahan hukum sekunder berkaitan dengan bahan-bahan hukum yang menjelaskan peraturan perundang-undangan, yakni RUU Industri Pertahanan, Doktrin, dan lain-lain. Sedangkan bahan hukum tersier berupa tulisan-tulisan dari jurnal, majalah, media social, dan lain-lain. Teknis Analisis data yang digunakan dalam penelitian ini adalah deskriptif analisis normatif, yakni pemaparan dan penggambaran peraturan perundang-undangan disertai analisis yang bersifat preskriptif.

\section{PEMBAHASAN}

\subsection{Kedudukan Surat Keputusan Nomor 6572K/70/MEM/2016 yang Dikeluarkan oleh Pelaksana Tugas Menteri ESDM Dihubungkan dengan Undang - Undang Nomor 30 Tahun 2014 tentang Administrasi Pemerintahan}

Kedudukan serta Keputusan Menteri Pelaksana Tugas Energi dan Sumber Daya Mineral menyangkut tentang Pembubaran Unit-Unit Ad Hoc di Lingkungan Kementerian ESDM. Pertama-tama akan diuraikan terlebih dahulu batas-batas Kewenangan Menteri Pelaksana Tugas Energi dan Sumber Daya Mineral dalam membentuk surat keputusan secara umum, yang kemudian akan dibahas mengenai kedududukan surat keputusan menteri secara umum.

Adapun kewenangan pelaksana tugas menteri ESDM dalam menjalankan tugasnya pada dasarnya telah ditentukan oleh peraturan perundang-undangan, yaitu kewenangan menteri pelaksana tugas dalam menjalankan tugasnya tidak sama dengan kewenangan menteri definitif. Pada dasarnya, terdapat pembatasan terhadap kewenangan menteri pelaksana tugas dalam menjalankan tugasnya. tugasnya ini dibatasi oleh : masa atau tenggang waktu kewenangan, wilayah atau daerah berlakunya kewenangan, dan cakupan bidang atau materi kewenangan.

Pada prinsipnya, surat keputusan menteri merupakan pelaksana dari ketentuan peraturan perundang-undangan. Akan tetapi tidak semua jabatan menteri dapat

${ }^{3}$ Sunaryati Hartono, Penelitian Hukum di Indonesia Pada Akhir Abad ke-20, Alumni, Bandung, 1994, hlm. 134. 
diperbolehkan untuk membentuk suatu surat keputusan. Hal ini dikarenakan adanya perbedaan sumber kewenangan yang menjadi batasan untuk menteri bertindak.

Oleh sebab itu, tidaklah mudah untuk menentukan apakah suatu keputusan itu benar-benar merupakan keputusan yang dikeluarkan sesuai dengan peraturan perundangundangan atau tidak. Produk-produk hukum semacam itu semata-mata hanya dilihat dari cara pembentukannya saja, bukan dari sifat materi atau isinya.

Berkaitan dengan permasalahan Surat Keputusan Menteri Pelaksana Tugas ESDM tentang Pembubaran Unit Organisasi Ad Hoc di Lingkungan Kementerian ESDM dapat diakui keabsahannya apabila : peraturan perundang-undangan memberikan kewenangan bagi terbentuknya keputusan dan/atau memerintahkan secara langsung pemabentukan keputusan tersebut; materi muatan keputusan tersebut sesuai dengan yang ditentukan peraturan perundang-undangan; dan dasar hukum kewenangannya dalam membentuk keputusan tersebut dirumuskan secara kronologis sesuai hierarki peraturan perundangundangan.

Akan tetapi, surat Keputusan Menteri Pelaksana Tugas ESDM tentang Pembubaran Unit Organisasi Ad Hoc di Lingkungan Kementerian ESDM tidak memiliki keabsahan hukum karena terdapat kecacatan terhadap aspek kewenangan, aspek prosedur maupun aspek substansinya.

\subsection{Akibat Hukum Terhadap Surat Keputusan Nomor 6572K/70/MEM/2016 yang Dikeluarkan oleh Pelaksana Tugas Menteri ESDM Dihubungkan dengan Undang - Undang Nomor 30 Tahun 2014 tentang Administrasi Pemerintahan}

Suatu keputusan atau ketetapan (beschikking) dapat dikatakan "tidak sah (nietrechtsgeldige)" apabila dibentuk menurut cara lain atau telah memberinya isi lin daripada yang secara langsung telah ditetapkan oleh perturan perundang-undangan yang menjadi dasar terbentuknya keputusan tersebut. Selama keputusan atau ketetapan (beschikking) belum dibatalkan, keputusan atau ketetapan (beschikking) itu "sah" (rechtsgeldige).

Penting untuk diperhatikan bahwa, "sah" atau "tidak sah" nya suatu keputusan atau ketetapan (beschikking) ada pada ranah validitasnya, bukan pada ranah efektifitasnya. Suatu norma hanya dianggap valid apabila norma tersebut termasuk kedalam suatu sistem norma. Sedangkan efektifitas adalah kondisi diamana norma-norma tersebut benar-benar 
diterapkan dan dipatuhi (dalam pengertian subjek hukum berbuat sesuai dengan norma tersebut). Suatu norma dikatakan valid bukan karena norma tersebut efektif.

Berdasarkan hal ini dapat diketahui bahwa, penyebutan suatu keputusan atau ketetapan (beschikking) sebagai "niet-rechtsgeldige" atau "tidak sah" bukanlah yang dapat dilakukan secara asal-asalan. Suatu keputusan atau ketetapan (beschikking) tidak dapat dikatakan "tidak sah" hanya dengan melihat terdapat suatu permasalahan dalam pelaksanaan keputusan atau ketetapan (beschikking) tersebut. Suatu keputusan atau ketetapan (beshikking) hanya bisa diakatakan "tidak sah" apabila terdapat pertentangan dengan ketentuan peraturan perundang-undangan yang menjadi dasar bagi terbentuknya keputusan itu, yakni dalam cara pembentukannya dari sisi isinya.

Berkenaan dengan pembentukannya, Surat Keputusan Menteri Pelaksana Tugas dalam Penelitian ini, dapat disimpulkan bahwa Surat Keputusan Surat Keputusan Menteri Pelaksana Tugas ESDM Nomor 6572 K/70/MEM/2016 tentang Pembubaran Unit Organisasi Ad Hoc Di Lingkungan Kementerian ESDM ini "tidak sah (nietrechtsgeldige)", karena terdapat suatu pertentangan dengan cara pembentukannya dan sumber kewenangan dalam pembentukannya.

Namun, dalam permasalahan ini terdapat pendapat lain dimana Surat Keputusan Nomor 6752 K/70/MEM/2016 Tentang Pembubaran Unit Organisasi Ad Hoc di Lingkungan Kementerian Energi dan Sumber Daya Mineral yang dikeluarkan oleh Luhut Binsar Pandjaitan selaku PLT menteri ESDM yang dapat dikatakan sah secara prosedur apabila sudah mendapatkan izin dari presiden.

Bagaimanapun PLT menteri merupakan pembantu presiden dalam menjalankan pemerintahan atau selaku pelaksana teknis pemerintahan,sehingga terhadap Surat Keputusan yang dikeluarkan oleh PLT menteri tersebut dapat dikatakan sebagai bentuk diskresi / fries ermessen. Menurut Pasal 1 ayat (9) Undang-Undang Nomor 30 Tahun 2014 tentang Administrasi Pemerintahan diskresi / fries ermessen adalah Keputusan dan/atau tindakan yang ditetapkan dan/atau dilakukan oleh pejabat pemerintahan untuk mengatasi persoalan konkret yang dihadapi dalam penyelenggaraan pemerintahan dalam hal peraturan perundang-undangan yang memberikan pilihan, tidak mengatur, tidak lengkap atau tidak jelas, dan/atau adanya stagnasi pemerintahan.

Surat Keputusan menteri pelaksana tugas ESDM Nomor 6572 K/70/MEM/2016 tentang Pembubaran Unit Organisasi Ad Hoc Di Lingkungan Kementerian ESDM ini telah mengesampingkan asas kemanfaatan yang dimana seharusnya asas kemanfaatan menjadi 
bagian penting daam pejabat pemerintahan membuat suatu keputusan ataupun tindakan, terutama lagi permasalahan sektro energi dan sumber daya mineral ini merupakan perihal yang sangat strategis karena mempunyai peran yang cukup banyak dalam pembangunan nasional.

Berdasarkan penjelasan-penjelasan diatas yang telah diuraikan di atas, Penulis menyimpulkan bahwa Surat Keputusan Menteri Pelaksana Tugas ESDM Nomor 6572 K/70/MEM/2016 tentang Pembubaran Unit Organisasi Ad Hoc Di Lingkungan Kementerian ESDM telah melanggar Pasal 31 ayat (1) Undang-Undang Nomor 30 Tahun 2014 Tentang Admininstrasi Pemerintahan yang berbunyi :

(1) Penggunaan diskresi dikategorikan mencampur adukan wewenang apabila :

a. Menggunakan diskresi tidak sesuai dengan tujuan wewenang yang diberikan;

b. Tidak sesuai dengan ketentuan Pasal 26, Pasal 27, Pasal 28; dan/atau

c. Bertentangan dengan AUPB.

Akibat hukum dari penggunaan diskresi yang dimaksud dalam Pasal 31 ayat (1) Undang-Undang Nomor 30 Tahun 2014 Tentang Admininstrasi Pemerintahan adalah dapat dibatalkan.

\section{BUKU - BUKU}

\section{DAFTAR PUSTAKA}

Abdul Ghoffar, 2009, perbandingan Kekuasaan Presiden Indonesia Sebelum Perubahan Undang - Undang dasar Negara Republik Indonesia Tahun 1945 dengan Delapan Negara Maju, Kencana, Jakarta.

Ateng Syafrudin, 2000, Menuju Penyelenggaraan Pemerintahan Negara yang Bersih dan Bertanggung Jawab, Jurnal Pro Justisia Edisi IV, Universitas Parahyangan, Bandung.

Bagir Manan, 1992, Dasar-dasar Perundang-undangan Indonesia, Ind-Hill.Co, Jakarta. 1999, Lembaga Kepresidenan, Gama Media, Yogyakarta. , 2003, Teori dan Politik Konstitusi, FH UII Press, Jakarta 2003.

C.S.T. Kansil, 2005, Sistem Pemerintahan Indonesia, Edisi Revisi, Bumi Aksara, Jakarta.

E. Utrecht, 1990,Pengantar Hukum Administrasi Negara Indonesia, T. Ichtiar Baru, Jakarta.

Faried Ali, 2012, Hukum Tata Pemerintahan Heteronom dan Otonom, Refika Aditama, Bandung.

H.A.S Natabaya, 2006, Sistem Peraturan Perundang-undangan Indonesia, Sekretariat Jenderal Mahkamah Konstitusi RI, Jakarta. 
H. A. Muin Fahmal, 2008, Peran Asas-asas Umum Pemerintahan Yang Layak Dalam Mewujudkan Pemerintahan Yang Bersih, penerbit Kreasi Total Media, Yogyakarta.

Indroharto, 1991, Usaha Memahami Undang-Undang tentang Pengadilan Tata Usaha Negara, cetakan Kedua, Pustaka Sinar Harapan, Jakarta.

-------------, 1993, Usaha Memahami Undang-Undang tentang Peradilan Tata Usaha Negara, Buku I. Sinar Harapan, Jakarta.

1999, Perbuatan Pemerintah Menurut Hukum Publik dan Hukum

Perdata, LPP HAN, Jakarta.

Irfan Fachruddin, 2004, Pengawasan Peradilan Administrasi Terhadap Tindakan, Alumni, Bandung.

J. Salusu, 1996, Pengambilan Keputusan Stratejik: Untuk Organisasi Publik dan Organisasi Nonprofit, Grasindo,Jakarta.

Jimly Asshiddiqie, 2006, Perkembangan dan Konsolidasi Lembaga Negara Pasca Reformasi, Seretariat Jenderal dan kepaniteraan Mahkamah Konstitusi Republik Indonesia, Jakarta.

, 2010, Perihal Undang-Undang, Rajawali Pers, Jakarta.

Jakarta.

Kuntjoro Purbopranoto, 1978, beberapa Catatan Hukum Tata Pemerintahan dan Peradilan Administrasi Negara, cetakan ke-2, Alumni, Bandung.

Lutfi Effendi, 2004,Pokok-Pokok Hukum Administrasi, Bayumedia Publishing, Malang.

Maria Farida, 2007, Ilmu Perundang-Undangan: Proses dan Pembentukannya, Kanisius, Yogyakarta.

M. Daud Silalahi, 1982, Hukum Antar Wewenang, LITERA, Bandung.

Mochtar Kusumaatmadja, 1975, Pengantar Hukum Tata Usaha Negara, Alumni, Bandung.

Muchsan, 1981, Beberapa catatan penting hukum administrasi negara dan peradilan administrasi negara di Indonesia. Liberty. Yogyakarta. hlm. 73.

Munir Fuady, 2002, Perbuatan Melawan Hukum: Pendekatan Kontemporer, $\quad$ PT. Citra Aditya Bakti.

Ni'matul Huda, 2005, Negara Hukum, Demokrasi dan Judisial Review, UII Pers, Jakarta.

Nomensen Sinamo, 2010, Hukum Administrasi Negara, Jala Permata $\quad$ Aksara, Jakarta.

Parlin M. Mangunsong, Pembatasan Kekuasaan Melalui Hukum Administrasi, dalam Dimensi -Dimensi Pemikiran Hukum Administrasi Negara, UII Press, Yogyakarta.

Philipus M. Hadjon, 1994, Tentang Wewenang, Universitas Airlangga, Surabaya.

Perc\&stensil Jumali, Surabaya. 
1997, Tentang Wewenang, Liberty, Yogyakarta.

University Press, Yogyakarta.

2004, Pengantar Hukum Administrasi Indonesia, Gadjah Mada , 2005, Pengantar Hukum Administrasi Negara :Introduction to the Administrative Law, Gadjah Mada University Press, Yogyakarta.

Raisul Muttaqien, Hans Kelsen: Teori Umum Hukum dan Negara (Terjemahan), $\quad$ Nusa Media,Bandung.

Ridwan HR, 2006, Hukum Administrasi Negara, PT. Raja Graindo Persada, Jakarta. , 2010, Hukum Administrasi Negara, Cet.9,Rajawali Pers, Jakarta. ,2013, Hukum Administrasi Negara, Cet 9, Rajawali, Jakarta.

Riant Nugroho, 2008, Public Policy: Teori Kebijakan-Analisis Kebijakan-Proses Kebijakan, Perumusan, Implementasi, Evaluasi, $\quad$ Risk Managament dalam Kebijakan Publik, Kebijakan Sebagai Fifth Estate, Metode Penelitian Kebijakan, Elex Media Komputindo, Jakarta.

Rosjidi Ranggawidjadja, 1987, Pengantar Ilmu Perundang-Undangan: Dasar, Jenis dan Teknik Membuatnya, Bina Aksara, Jakarta.

Safri Nugraha, 2007, Hukum Administrasi Negara, Edisi Revisi, Depok: Center for Law and Good Governnance Studies (CLGS) FHUI. , 2007, Laporan Akhir Tim Kompendium Bidang Hukum Pemerintahan yang Baik. BPHN. Jakarta.

SF. Marbun, 2009, Pokok-pokok Hukum Administrasi Negara, Liberty, Yogyakarta.

Sjachran Basah, 1985, Eksistensi dan Tolak Ukur Peradilan Administrasi di Indoneisa, Alumni, Bandung.

,1992, Perlindungan Hukum Terhadap Sikap TIndak Administrasi Negara, Alumni, Bandung, hlm. 53

Sri Mamudji, 2007, Hukum Administrasi Negara, CLGS FH UI, Depok.

Sunaryati Hartono, 2011, Bandung, Penelitian Hukum Indonesia Pada Akhir Abad Ke20, Alumni, Bandung.

Ujang Charda S, 2009, Disiplin Ilmu Hukum : Sebuah Pengembaraan dalam Memahami Fondasi, Struktur, Arsitektur \& Kesejarahan Ilmu Hukum, Bungo Abadi, Bandung.

Wirjono Prodjodikoro, 2000, Perbuatan Melanggar Hukum; Dipandang Dari Sudut Hukum Perdata, Mandar Maju, Bandung.

\section{PERATURAN PERUNDANG - UNDANGAN}

Undang - Undang Nomor 30 Tahun 2014 Tentang Administrasi Pemerinahan.

Surat Keputusan Menteri Pelaksana Tugas Nomor 6572 K/70/MEM/2016 tentang Pembubaran Unit Organisasi Ad Hoc Di Lingkungan Kementerian Energi dan Sumber Daya Mineral. 


\section{SKRIPSI, ARTIKEL, DAN JURNAL}

Bambang Giyanto, Kewenangan Pejabat Publik Pengganti Dalam Pengambilan Keputusan Kebijakan Publik, Jurnal, diakses pada $\quad$ tanggal 5 Februari 2018, pukul 23.00 WIB.

http://research.ui.ac.id/research/wp-content/uploads/2015/03/Presentasi-m enteri-esdm150330-Rakor-MESDM-dengan-BPK-RI.pdf

Wendi Triana, Batas Kewenangan Menteri Hukum dan Hak Asasi Manusia Terhadap Partai Politik dan Kedudukan Surat Keputusan Menteri Hukum dan Hak Asasi Manusia Menyangkut Kepengurusan Partai Politik, Skripsi, Fakultas Hukum UNPAD, Bandung; 2017.

\section{MEDIA ELEKTRONIK}

Aloysius Diaz Aditya, Menteri ESDM Klaim CoE Energi Bersih Siap Beroperasi,https://eksplorasi.id/menteri-esdm-klaim-coe-energi-bersih siapberoperasi/2230, diakses pada tanggal 25 Juli 2018, Pukul 22.24 WIB.

Ferial, Center of Excellence Energi Bersih Siap Beroperasi, http://ebtke.esdm.go.id/post/2016/04/03/1176/center.of.excellence.energi.bersih.sia p.beroperasi, diakses pada tanggal 25 Juli 2018, Pukul 22.32 WIB.

Gayus T. Lumbuun, Pro Kontra Rencana Pembuatan Peraturan untuk Melindungi Pejabat Publik, http://www.hukumonline.com, diakses tanggal 16 September 2018.

Micom , Luhut Bedah Ulang Struktur Kementerian ESDM, http://m.mediaindonesia. com/read/detail/63391-luhut-bedah-ulang-stru ktur-kementerian-esdm, diakses pada tanggal 25 Juli 2018, Pukul 23.54 WIB.

Ronna Nirmala, Alasan Luhut bubarkan tim adhoc bentukan Sudirman Said,https://beritagar.id/artikel/berita/alasan-luhut-bubarkan-tim-adhoc-bentukanSudirman -said, diakses pada tanggal 25 Juli 2018, Pukul 20.43 WIB

Safrezi Fitra, Masalah Kelistrikan, Pemerintah Bentuk Unit Baru,

https://katadata.co.id/berita/2015/01/13/masalah-kelistrikan-pemerintah-bentuk-unit-baru, diakses pada tanggal 25 Juli, Pukul 23.08 WIB.

Wicaksana Dramanda, Pejabat Negara Dan Pejabat Pemerintah, www.hukumonline.com/klinik/detail/lt52f38f89a7720/pejabat-negara-dan-pejabatpemerintahan, diakses pada tanggal 5 Februari 2018, Pukul 00.01 WIB. 